\title{
Design and construction of the Cadet-M unmanned marine platform using alternative energy
}

\author{
Mikhail Kadyrov ${ }^{1}$, Pavel Greshnikov ${ }^{1}$, Semyon Maltsev ${ }^{1}$, Alexey Maistro, ${ }^{1,}$, Alexander Pereverzev ${ }^{1}$, Kirill Kiselev ${ }^{1}$, Andrey \\ Durnev $^{1}$, Egor Starobinskii ${ }^{1}$, and Pavel Buldakov ${ }^{1}$ \\ ${ }^{1}$ Peter the Great St. Petersburg University, St. Petersburg, Russia
}

\begin{abstract}
Environmental monitoring has become an urgent task in recent years in connection with the deterioration of the environmental situation caused by industrialization [1]. Usually, manned vessels with measuring equipment and personnel serving it on board were used for these purposes, but with the development of technology, full automation of this process became possible. The problem of the need to use human resources is solved by applying an autonomous vessel control system. However, the big problem remains, which is the need to refuel the vessel in connection with the finite amount of stored energy. This problem is solved by using renewable energy, an example of which is solar energy, on measuring platforms. This article will discuss methods for developing platforms controlled by the autopilot and using solar energy, using the Cadet-M platform as an example.
\end{abstract}

\section{Introduction}

Unmanned control technologies are currently advanced technologies in the field of patrolling and monitoring of water areas. [2] The use of manned vessels is inconvenient due to the needs of the person on board. As a rule, such vessels need periodic return to shore in order to replenish food and fuel supplies. The problems associated with keeping on board a person are solved using unmanned control systems. The use of alternative renewable energy solves the problem of the need to refuel the vessel. Alternative energy is energy whose source is different from traditional sources: coal, gas, nuclear fuel, oil, etc .; more often used in the context of limited fossil fuel sources and the presence of such emissions of harmful greenhouse gases into the atmosphere when used [3]. One type of alternative energy is solar energy. When using this type of energy, converted into electrical energy using solar panels, there is the possibility of continuous operation of the measuring platform.

\section{Methods}

\subsection{The design of the platform}

The Cadet-M hull is designed as a catamaran in order to maximize wave stability $[4,5]$. Cadet-M has a carbon fiber float housing for lightweight construction [6]. To increase the operating time, heterostructured solar panels $[6,7,8,9,10]$ on a silicon substrate with high efficiency were used as well as a battery management system (BMS) [11,12], which allows autonomous monitoring of up to two days. The platform is equipped with sonar, a water sampling system, a radiation sensor, a robot arm, a radar and other instruments and devices. Cadet-M can carry up to $30 \mathrm{~kg}$ of payload and has 3 quick-detachable modules for this.

Distinctive features of this autonomous platform are modularity and collapsibility. These properties make it easy to transport Cadet-M. They also allow you to modify the platform to fulfill your tasks by adding the necessary modules for this.

Based on the above, a CAD model of the Cadet-M with linear dimensions of $2 \times 2 \times 1.5 \mathrm{~m}$ was built, Fig. 1 .

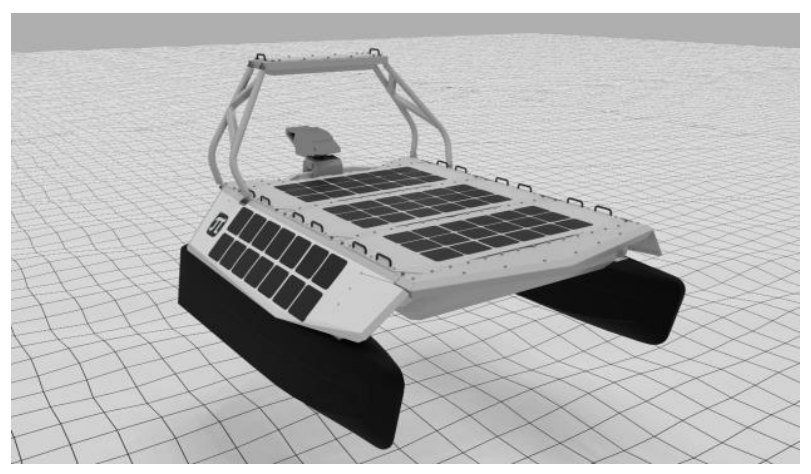

Fig. 1. Cadet-M.

\subsection{Platform control}

Cadet-M can be controlled remotely in several variations. The first of them is control by remote control. Using the joysticks located on the console, the researcher sets the course to be followed by Cadet-M, as well as adjusts its speed. The second variation of Cadet-M

\footnotetext{
*Corresponding author: surios@yandex.ru
} 
control is to set the exact coordinate at which the platform will arrive. This option is suitable if you want to move the Cadet-M to a specific point where measurements will be made. The third variation of management setting the route (ie, several points), which will follow the unmanned platform. This type of control is used when a task involves taking measurements in a specific area.

\subsection{Remote control software}

To control the platform, a management program was developed, the interface of which is shown in Fig.2.

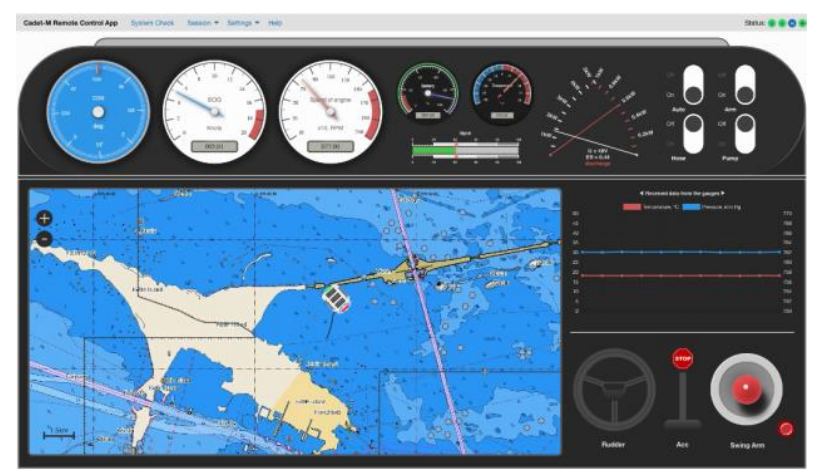

Fig. 2.

This software allows the user to control the unmanned vehicle remotely or use the autonomous mode. The autonomous mode means performing a specific task without human intervention. Tasks can be set in different ways: plotting points on the map through which the drone needs to pass, setting an area on the map, which the drone will monitor, or setting a specified route that the drone will follow. The followed track is indicated on the map.

The developed software also enables the user to view readings from multiple sensors in real time and finding out the remaining battery capacity. The software was developed using a modular architecture approach in order to provide flexibility and ease of expansion of functionality. The software is based on a three-level intelligent control system [13, 14, 15].

\section{Results}

An unmanned Cadet-M platform was created that meets the specified requirements. Preliminary tests showed that the hardware-software complex is working correctly and the platform follows a predetermined course in a given water area.

\section{Conclusions}

The constructed platform due to complete autonomy allows saving human and financial resources when solving the tasks assigned to it. According to its characteristics, Cadet-M is suitable for many tasks, the most popular of which are:
- environmental monitoring and diagnosis of the state of the underwater oil and gas pipeline using an infrared camera;

- mapping of depths of the water area;

- compilation of volumetric maps of chemical and radioactive contamination of water.

\section{References}

1. Jasdeep Kaur Dhami, Harminder Singh, Manish Gupta. INDUSTRIALIZATION AT THE COST OF ENVIRONMENT DEGRADATION- A CASE OF LEATHER AND IRON AND STEEL INDUSTRY FROM PUNJAB ECONOMY. Innovative Journal of Business and Management 2: 1. Jan - Feb (2013). 19 21.

2. Mariusz Specht, Cezary Specht, Henryk Lasota, Piotr Cywi'nski. Assessment of the Steering Precision of a Hydrographic Unmanned Surface Vessel (USV) along Sounding Profiles Using a Low-Cost Multi-Global Navigation Satellite System (GNSS) Receiver Supported Autopilot. Sensors 2019. 2019. 3939.

3. Salikeeva S.N., Galeeva F.T. Overview of methods for producing alternative energy // Bulletin of Kazan Technological University. 2012 p. 57-59.

4. Catamaran boat. Patent Number: 5,188,049. Inventor: Lawrence J. Graf. Filed: Jan. 14, 1992. Date of Patent: Feb. 23, 1993.

5. S. S. Khodjaev. Advantages of multi-hull vessels over single-hull vessels. Innovation in modern science. Materials of the XII International Spring Symposium: Collection of scientific papers. Center for Scientific Thought. Publisher: Publishing House "Pero" (Moscow). 2016 c. 170-174.

6. Makusheva N. Yu., Kolosova N. B., SPbPU. Comparative analysis of metal reinforcement and reinforcement made of composite materials. Magazine: CONSTRUCTION OF UNIQUE BUILDINGS AND STRUCTURES. Publisher: Production, research and design. 2014. Pages: 60-72.

7. M. Sabzia, S.H.Mousavi Anijdan. Microstructural analysis and optical properties evaluation of sol-gel heterostructured $\mathrm{NiO}-\mathrm{TiO} 2$ film used for solar panels. Ceramics International. Volume 45, Issue 3, 15 February 2019, Pages 3250-3255.

8. S.N. Abolmasov, A.S. Abramov, G.A. Ivanov, E.I. Terukov, K.V. Emtsev, I.A. Nyapshaev, A.A. Basel, S.P. Gubin, D.Yu. Kornilov, S.V. Tkachev, V.P. Kim D.A. Ryndin, V.I. Levchenkova. Heterostructured solar cells based on crystalline silicon with a contact grid printed on an inkjet printer. // Letters to the ZhTF, t. 43 (1), No. 1, pp. 74-79, 2017.

9. A. A. Bobkov, A. I. Maximov, V. A. Moshnikov, P. A. Somov, E. I. Terukov. Zinc-oxide-based nanostructured materials for heterostructure solar cells. Semiconductors. October 2015, Volume 49, Issue 10, pp 1357-1360.

10. A P Yagunov, T A Gavrikova, V A Zykov and I S Polukhin. Si/ZnxCd1-xTe heterostructures with different $\mathrm{Zn}$ contents: growth, electrical and photoelectrical 
properties. 2016 Journal of Physics: Conference Series, Volume 690, conference 1.

11. Buldakov P.Yu., Maistro A.S., Pereverzev A.E., , Starobinskii E.B., Zarubin I.A. Researching in improving battery lifetime by using cell balancing technologies. BOOK OF ABSTRACT SXLVI International Conference "Advanced Problems in Mechanics". 2018. p. 118-119.

12. V. Elistratov, I. Kudryasheva. Regimes, management and economics of energy complexes on the basis of renewable energy sources for autonomous power supply. E3S Web Conf. Volume 124, 2019 International Scientific and Technical Conference Smart Energy Systems 2019 (SES-2019).

13. Pereverzev A.E., Starobinsky E.B., Buldakov P.Yu. Study of approaches to the construction of an automatic control system for a crewless boat (BEC). Collection of Abstracts XLIV International Youth Scientific Conference "Gagarin Readings - 2018". Volume 2. pp. 33-34.

14. A. Vassiliev, V.Samarin, D. Raskin, E. Evseev, V. Veris, I.Peschinski, D. Cabezas, Yo. Kurniawan. Designing The Built-In Microcontroller Control Systems of Executive Robotic Devices Using The Digital Twins Technology. 2019 International Conference on Information Management and Technology (ICIMTech), 19 September 2019. 19 September 2019. DOI: 10.1109/ICIMTech.2019.8843814.

15. K.M. Passino. Intelligent control for autonomous systems. IEEE Spectrum. Jun 1995. Volume: 32 , Issue: 6. 